\title{
A Look at DoD Support of Research: Maintaining the Pipeline for Academic Basic Research
}

The Department of Defense (DoD) has been a significant supporter of academic research for almost 60 years. Following the successful contribution of academic scientists and engineers to national security during the Second World War the U.S. government sought to define, for the postwar era, the role of university scientists for peacetime and national security purposes. President Roosevelt asked his Science Advisor, Vannevar Bush, to study the issue, and in 1945 Bush delivered his seminal work, "Science--The Endless Frontier" to then President Truman. In this work, Bush argued for federal support of unfettered basic research and the creation of a self-governing National Research Foundation (NRF) with divisions of medical research, natural sciences, and national defense. He also proposed a linear model for research, consisting of basic research, applied research, and advanced development. The self-governing aspect of his proposal caused significant controversy, and the NRF was never established. However, the debate that followed resulted in the creation of the National Science Foundation (NSF) in 1950. The Department of Defense independently determined to support academic research, and in 1946 the Office of Naval Research (ONR) was established to support advanced research in nuclear physics and other topics of interest to the Navy. The other services soon followed suit, and the Army Research Office (ARO) was established in 1951 and the predecessor of the Air Force Office of Scientific Research (AFOSR) was established in 1952. The Defense Advanced Research and Projects Agency (DARPA) was established in 1958 to focus research and development activity upon high payoff projects of interest to national security. Support for materials science and engineering has always been a primary focus of the DoD research effort, and all DoD services and agencies have sustained significant efforts directed toward advanced materials science and technology, with about $30-40 \%$ of the research budget directed toward these activities.

The main focus of the Tri-Services' offices was to support basic research and to work with the academic community. ONR was initially organized to counter fears that government sponsorship of university research would be restrictive, burdened with bureaucratic rules, or subject to political pressures. Scientists were encouraged to propose their own projects. No progress reports were required, and refereed publication in the open literature was sufficient evidence of progress. Support funds were made available for graduate assistants and summer faculty support and awards were multiyear and renewable. The linear model proposed by Bush was adopted and, for the most part, is still in effect.

Although the science and technology (S\&T) support funds provided to the department by Congress consist of basic research, applied research, and advanced development (denoted as 6.1, 6.2, and 6.3 in the federal budget), ARO and AFOSR only manage funds in the basic research (6.1) category. AFOSR manages all of the basic research supported by the Air Force, and ARO only manages a portion of the Army's basic research, the remainder managed by other Army organizations. ONR is now vertically integrated and manages funds in the $6.1,6.2$, and 6.3 categories. DARPA has a small 6.1 budget, amounting to about $\$ 65$ million of a $\$ 2$ billion budget.

\section{DoD provides about $\$ 300$ million annually in support for academic research in areas related to materials science and engineering.}

Although many program changes have occurred since the early days, the strong focus of the basic research program upon academic research remains. Many fundamental discoveries sponsored by the basic research program have resulted in advances of worldwide significance, including a significant fraction of DoDsponsored work closely related to materials science that resulted in Nobel Prizes. DoDsupported research in materials science and engineering has been fundamental in establishing technology advances that underlie the development of major industries, such as those based upon semiconductors, computers, the Global Positioning System (GPS), the Internet, and others.

Research, of course, requires funds and Congress annually provides the department support funds for science and technology. For FY 1999 the department's S\&T budget is $\$ 7.8$ billion, with $\$ 1.1$ billion allocated for basic research, and slightly more than $\$ 3$ billion each for applied research and advanced development. Of the S\&T funds, approximately $60 \%$ of the basic research, $14 \%$ of the applied research, and $4 \%$ of the advanced devel- opment funds go to support research and development in academic institutions. That is, DoD provides about $\$ 1$ billion annually for university-based research. Although the funding levels have fluctuated historically, the recent trend has been down. Since 1993 the purchasing power of the budgets have declined by about $30 \%$ ( $\$ 400$ million) for basic research, and about $16 \%$ ( $\$ 570$ million $)$ for applied research.

As a mission agency, DoD supports research in areas that are viewed as likely to provide advances that will eventually impact national security. Support tends to be focused in the hard sciences and engineering, and materials engineering and science are major topics of interest. Although DoD provides about $\$ 1$ billion annually of academic research support, this amounts to less than $8 \%$ of the national investment in basic research. Yet DoD accounts for fully $55 \%$ of the external research support in engineering, including $64 \%$ in electrical engineering, $46 \%$ in computer science, and $36 \%$ in metallurgy and materials. Currently, DoD provides about $\$ 300$ million in support for academic research in areas related to materials science and engineering, including research funds for focused efforts in structural, composite, electronic, photonic, biological, and novel materials.

DoD support for basic research in materials science and engineering will continue. Materials research is on the eve of a new era, and the ability to fabricate novel materials with pre-determined properties offers the potential for major advances in a wide variety of systems. Nanotechnology, in particular, is a focus area of support, and entirely new types of materials are expected to result. Indeed, nanotubes based upon the carbon-based buckminsterfullerenes, with intriguing structural and electronic properties, have already been reported and are showing promise for practical application. Similarly, advances in materials research directed toward nanotechnology will affect diverse areas of DoD interest such as quantum devices, biological systems, advanced electronics and photonics, and novel composite and structural materials. We are in a period of rapid and exciting innovation, and advances in materials science and technology are fundamental to this effort.

R.J. TREW

R.J. Trew is the Director of Research in the Office of the Deputy Undersecretary of Defense for Science and Technology, U.S. Department of Defense. 